\title{
AKTIVITAS PENGHAMBATAN PEMBENTUKAN BATU GINJAL (Antinefrolithiasis) EKSTRAK ETANOL DAUN GEDI MERAH (Abelmoschus moschtus Medik) PADA TIKUS PUTIH JANTAN
}

\section{INHIBITORY ACTIVITY OF KIDNEY STONE FORMATION (Anti- nephrolithiasis) OF ETHANOL EXTRACT OF RED GEDI LEAVES (Abelmoschus moschatus Medik) IN MALEWHITE RATS}

\author{
Triana Riandani Djamhuri ${ }^{1^{*}}$, Yuliet ${ }^{1}$, Khildah Khaerati ${ }^{1}$ \\ ${ }^{1}$ Jurusan Farmasi, Fakultas MIPA,UniversitasTadulako, Palu.
}

Received 8 Desember 2015, Accepted 10 Januari 2016

\begin{abstract}
ABSTRAK
Gedi merah (Abelmoschus moschatus Medik) merupakan tanaman yang hanyadijumpai didaerah beriklim tropika seperti di Afrika dan Asia. Beberapa pengalaman masyarakat di daerah Manado menyatakan bahwa tanaman gedi merah dapat digunakan untuk mengobati berbagai jenis penyakit yang ada seperti batu ginjal. Oleh karena itu penelitian ini bertujuan untuk mengetahui aktivitas dan dosis yang efektif ekstrak daun gedi merah sebagai penghambat pembentukan batu ginjal. Ekstrak dibuat dengan cara maserasi menggunakan pelarut etanol 96\%. Pengujian aktivitas penghambatan pembentukan batu ginjal ini dilakukan dengan cara membagi hewan uji menjadi 6 kelompok. Setiap kelompok terdiri dari 3 ekor tikus putih jantan. Kelompok pertama (Kontrol normal) dan kedua (Kontrol negatif) diberikan Na.CMC 0,5\%; kelompok ketiga (Kontrol positif) diberikan Batugin Eliksir 2,7 m/kg BB sedangkan kelompok keempat, kelima, dan keenam secara berturut-turut diberikan ekstrak daun gedi merah sebesar 50, 100, dan 150 $\mathrm{mgkgBB}$. Setelah 2 jam semua kelompok perlakuan diberi induksi etilen glikol 0,75\% dan amonium klorida 2\% kecuali kelompok kontrol normal. Rasio bobot ginjal dan kadar kalsium diukur dan dihitung. Data dianalisis secara statistik dengan menggunakan ANOVA (Analysis Of Variance) dan dilanjutkan dengan uji LSD (Least Significantly Difference). Dapat disimpulkan bahwa, ekstrak etanol daun gedi merah memiliki aktivitas penghambatan pembentukan batu ginjal pada ketiga variasi dosis dan yang paling efektif adalah pada dosis $150 \mathrm{mgkgBB}$.
\end{abstract}

Kata kunci : Abelmoschus moschatus Medik, Antinefrolithiasis, Rasio Bobot Ginjal, Kadar kalsium.

\begin{abstract}
Red Gedi (Abelmoschus moschatus Medik) is a plant found only in tropical climate areas such as Africa and Asia. Some people's experience in Manado stated that red gedi plants can be used to treat various types of disease, one of them was kidney stones. Therefore, this study aimed to determine the activity and the effective dose of red gedi leaf extract as an inhibitor of kidney stone formation. The extract was prepared by maceration using ethanol $96 \%$. Inhibitory activity test of kidney stone formation was done by firstly dividing the labrats into 6 groups. Each group consisted of 3 male rats. Both the first group (Normal control) and the second group (Negative control) weregiven Na.CMC 0.5\%; the third group (Positive control) was given Batugin Elixir at a dose of $2.7 \mathrm{ml} / \mathrm{kgBW}$; while the fourth, fifth, and sixth were respectively given red gedileaf extract at doses of 50,100, and $150 \mathrm{mg} / \mathrm{kgBW}$. After 2 hours, all treatment groups were induced with $0.75 \%$ of ethylene glycol and $2 \%$ of ammonium chloride except for the normal control. Ratio of kidney weight and the level of calcium were then measured and calculated. Data obtained were statistically analyzed using ANOVA (Analysis Of variance) and continued with LSD (Least Significantly Difference). It can be concluded that ethanol extract of red gedileaves had inhibitory activity of kidney stones formation in all dose variation and the most effective one was at a dose of $150 \mathrm{mg} / \mathrm{kgBW}$.
\end{abstract}

Keywords: Abelmoschus moscathus Medik, Antinefrolithiasis, kidneyweightratio, levels of calcium

*Correspondence author : Triana R Djamhuri, Trianadjamhuri@gmail.com (ph : +62852-4102-7233) 


\section{PENDAHULUAN}

Ginjal dalam tubuh berfungsi sebagai filter untuk membersihkan darah atau cairan lainnya. Fungsi ini bertujuan agar bahan-bahan kimia yang terkandung dalam darah atau cairan tubuh lainnya tidak terbawa kembali oleh darah dan beredar ke seluruh tubuh. Sebagian kotoran hasil penyaringan ini akan dikeluarkan melalui ginjal bersama urin dan sebagian lagi mungkin tertinggal dan mengendap menjadi batu ginjal. Apabila endapan ini tidak dikeluarkan, maka akan menetap di ginjal atau berpindah ke kandung kemih cairan yang menyerupai plasma yang difiltrasi melalui dinding kapiler glomerulus ke tubulus renalis di ginjal. Perjalanan isi cairan sepanjang tubulus ginjal, isi cairan filtrat akan berkurang dan susunannya berubah akibat proses reabsorbsi tubulus dan proses sekresi tubulus untuk membentuk urin yang akan disalurkan ke dalam pelvis renalis (Ganong, 1995).

Batu (kalkulus) ginjal adalah batu yang terdapat dimana saja di saluran kemih. Batu yang paling sering dijumpai tersusun dari kristal-kristal kalsium. Komponen yang lebih jarang membentuk batu adalah struvit atau magnesium, amonium, asam urat, atau kombinasi bahan-bahan ini (Corwin, 2009 : 124). Batu ginjal terbentuk akibat kejenuhan air kemih, gangguan keasaman ginjal, dan menurunnya faktor penghambat pembentukan kristal pada orang dewasa sehat, $\mathrm{pH}$ urin berkisar antara 4,5-8,0 sedangkan $\mathrm{pH}$ urin rata-rata adalah 6,0 . Air kemih yang bersifat asam memudahkan terbentuknya batu kalsium dan asam urat, sedangkan air kemih yang bersifat basa memudahkan terbentuknya batu struvit (Suharjo. B dan Cahyono, 2009).

Berdasarkanhasil RISKESDAS

2013, prevalensi penderita batu ginjal berdasarkan wawancara terdiagnosis dokter di Indonesia sebesar 0,6\%. Prevalensi tertinggi di DI Yogyakarta $(1,2 \%)$, diikuti Aceh $(0,9 \%)$, Jawa Barat, Jawa Tengah, dan Sulawesi Tengah masing-masing sebesar $0,8 \%$. Prevalensi penyakit batu ginjal berdasarkan wawancara meningkat seiring dengan bertambahnya umur, tertinggi pada kelompok umur 55-64 tahun (1,3\%), menurun sedikit pada kelompok umur 6574 tahun $(1,2 \%)$ dan umur $\geq 75$ tahun $(1,1 \%)$. Prevalensi lebih tinggi pada lakilaki $(0,8 \%)$ dibanding perempuan $(0,4 \%)$, hal ini dikarenakan pada laki-laki memiliki hormon testosteron. Apabila hormon ini berlebih maka akan menyebabkan peningkatan oksalat oleh hati yang selanjutnya memudahkan terjadinya kristalisasi.(Anonim, 2013).

Pengobatan terhadap penyakit batu ginjal dapat dilakukan dengan cara melakukan pengobatan secara modern dan pengobatan alternatif seperti pengobatan tradisional. Pengobatan secara modern dapat dilakukan dengan cara gelombang kejut atau Extracorporeal Shock Wave Lithotripsy (ESWL), pembedahan terbuka (Percutaneus Nephrolithotomy), Ureteroscopic Stone Removal, atau dengan mengkonsumsi obat-obatan penghancur batu ginjal (Soeryoko, 2011).

Obat tradisional yang sering digunakan oleh masyarakat biasanya berupa tanaman-tanaman yang dapat menghancurkan batu ginjal. Tanaman yang telah diuji secara in vivo pada tikus jantan putih untuk mengatasi batu ginjal diantaranya adalah pegagan, tempuyung, daun kapuk randu, mentimun, bulbus bawang dayak, dan daun alpukat (Angreani Sekar, 2013; Ma'sum Selvia, 2013; Ardina dan Sutomo, 2008; ; Anggara A., 2009). Secara normal, pembentukan kalsium batu ginjal di hambat oleh flavonoid, kalium, magnesium, dan asam sitrat (Ari W Sundoyo, Bambang S, 2006). Senyawa flavonoid adalah suatu kelompok senyawa fenol yang terbesar ditemukan di alam. Kalsium pada batu ginjal diduga dapat membentuk senyawa kompleks dengan gugus -OH dari flavonoid sehingga membentuk Ca-flavonoid. Senyawa kompleks ini diduga lebih mudah larut dalam air, sehingga air yang ada dalam urin akan membantu kelarutan batu tersebut. Aktivitas diuretik flavonoid dapat membantu pengeluaran batu dari dalam ginjal yaitu dikeluarkan bersama urin, sementara kalium akan menyingkirkan kalsium dan berikatan dengan oksalat 
sehingga menjadi senyawa yang lebih mudah larut dalam air (Nisma, 2011).

$$
\text { Gedi merah (Abelmoschus }
$$

moschatus Medik) merupakan tanaman yang hanya dijumpai di daerah beriklim tropika seperti di Afrika dan Asia. Beberapa pengalaman masyarakat di daerah Manado menyatakan bahwa tanaman gedi merah dapat digunakan untuk mengobati berbagai jenis penyakit yang ada salah satunya yaitu batu ginjal (Fadhila, 2013). Tanaman gedi juga dapat meningkatkan fungsi penyaringan glomerular, mengurangi proteinuria, hyperplasia messangium yang dapat mengurangi kerusakan jaringan ginjal (Shao-Yu et al., 2006).

Berdasarkan penelitian yang telah dilakukan oleh Dama E (2014), menyatakan bahwa ekstrak etanol gedi merah memiliki aktivitas dalam melarutkan kalsium batu ginjal secara in vitro, namun belum ada penelitian yang dilakukan untuk mengetahui aktivitas ekstrak etanol gedi merah dalam menghambat batu ginjal secara in vivo. Penelitian ini dilakukan untuk mengetahui sejauh mana pengaruh ekstrak etanol gedi merah dalam menghambat pembentukan batu ginjal secara in vivo pada tikus jantan yang diberikan induksi etilen glikol dan amonium klorida.

\section{METODE PENELITIAN}

\section{Jenis Penelitian}

Jenis penelitian ini adalah penelitian eksperimen laboratorium dimana kelompok perlakuan dibagi menjadi 6 kelompok uji, masing-masing terdiri dari 3 ekor tikus putih yang diinduksi etilen glikol $0,75 \%$ dan amonium klorida $2 \%$ peroral.

\section{Waktu dan Tempat Penelitian}

Penelitian ini dilakukan sejak bulan Januari sampai Oktober 2015, bertempatdi Laboratorium FarmakognosiFitokimia, pemberian perlakuan dilakukan di Laboratorium Farmakologi-Biofarmasi Jurusan Farmasi, Fakultas Matematika dan Ilmu Pengetahuan Alam, dan pengujian dilakukan di laboratorium Ilmu Tanah Universitas Tadulako, Palu, Sulawesi Tengah.

\section{Persiapan Bahan Uji}

Bahan uji yang digunakan dalam penelitian ini adalah daun gedi merah (Abelmoschus moschatus Medik.) diperoleh dari kelurahan Gebang Rejo, Kecamatan Poso kota Kabupaten Poso Provinsi Sulawesi Tengah. Identifikasi tnaman dilakukan di Lembaga Ilmu Pengetahuan Indonesia (LIPI) Pusat Konservasi Tumbuhan - Kebun Raya Bogor. Serbuk daun gedi merah sebanyak $676 \mathrm{~g}$ diekstraksi dengan etanol 96\%sebanyak 2,5 L dengan menggunakan metode maserasi. Ekstrak etanol yang didapatkan kemudian dikumpulkan diuapkan dengan rotary evaporator hingga diperoleh ekstrak kental etanol daun gedi merah sebanyak 12,30 gram.

\section{Uji Penapisan Fitokimia (Harbone, 1987)}

Ekstrak etanol daun gedi merah yang telah didapatkan kemudian diuji kualitatif terhadap adanya senyawa flavonoid, saponin, steroid, terpenoid, alkaloid, dan tannin.

\section{Pengujian Aktivitas Penghambtan Pembentukan Batu Ginjal}

Hewan uji tikus putih jantan yang digunakan berjumlah 18 ekor dan masingmasing kelompok terdiri dari 3 ekor tikus yang dibagi secara acak.. Kelompok I adalah kelompok normal yang diberikan NaCMC. Kelompok II adalah kontrol negatif yang diberi Na CMC. Kelompok III adalah kontrol positif yang diberikan batugin eliksir. Kelompok IV,V dan VI sebagai kelompok uji diberi ekstrak etanol daun gedi merah dengan konsentrasi masing-masing $50 \mathrm{mg} / \mathrm{kg} \mathrm{BB} ; 100 \mathrm{mg} / \mathrm{kg} \mathrm{BB}$; dan 150 $\mathrm{mg} / \mathrm{kg}$ BB secara peroral. Setelah 2 jam kelompok 2-6 diberikan induksi batu ginjal.Semua perlakuan tersebut dilakukan selama 10 hari. Pada hari ke 10 setelah perlakuan tikus dipuasakan selama 16 jam, hanya diberikan air minum secukupnya saja. Pada hari ke 11 dilakukan pembedahan pada tikus. Terlebih dahulu tikus dikorbankan dengan menggunakan eter, selanjutnya abdomen dibuka kemudian diambil ginjalnya dan dilakukan penimbangan bobot ginjal serta analisis kadar kalsium ginjal. 
Analisis karakteristik Ginjal

Setelah perlakuan selesai, dilakukan pengamatan terhadap masingmasing ginjal hewan coba. Secara hati-hati kedua ginjal diambil, masing-masing ginjal ditimbang, dan dihitung rasio bobot ginjal/ $100 \mathrm{~g}$ bobot tikus (Wijaya Sumi, dan Farida L.,2005).

\section{Analisis kandungan Kalsium pada Ginjal}

Ginjal masing-masing tikus diletakkan di cawan penguap lalu dimasukkan ke dalam oven dengan $100^{\circ} \mathrm{C}$ selama 24 jam. Setelah ginjal kering, ginjal digerus di mortir kemudian dimasukkan ke dalam gelas piala $25 \mathrm{ml}$, ditambahkan $5 \mathrm{ml}$ asam nitrat pekat dan $2 \mathrm{ml}$ asam perkolat, dibiarkan selama 24 jam. Setelah itu sampel didekstruksi basah hingga larutan tidak berwarna dan hingga volumenya 1-2 $\mathrm{ml}$. Hasil dekstruksi didinginkan kemudian disaring di dalam labu ukur $25 \mathrm{ml}$ dan dicukupkan dengan aquadest. Dipipet 0,5 $\mathrm{ml}$ dari dalam labu ukur kemudian dimasukkan kedalam tabung reaksi dan ditambahkan dengan $\mathrm{LaCl}_{3}$ sebanyak 4,5 $\mathrm{ml}$. Selanjutnya diukur kadar kalsiumnya dengan menggunakan alat flame fotometer.

\section{Analisis Data}

Hasil pengamatan karakteristik ginjal adalah dengan menghitung rasio bobot ginjal semua kelompok tikus, untuk menghitung rasio bobot ginjal tiap tikus menggunakan rumus sebagai berikut : (Boesro S, Warya S, Rosdiana T dan Ade Z, 2010).

$$
\text { Rasioginjal }\left(\frac{g}{100 g}\right)=\frac{\text { beratginjaltikus }(g)}{\text { BBtikus }(100 g)}
$$

Sedangkan hasil data kadar kalsium pada ginjal, sebelum dilakukan uji statistik hasil data flame fotometer kadar kalsium pada ginjal dihitung dengan rumus berikut :

$$
\begin{gathered}
\% \text { KadarCa }=\text { ppm } \\
\text { kurva } \times\left(\frac{\text { volumeekstrak }}{1000}\right) \\
\times\left(\frac{100 m g}{\text { beratsampel }}\right)
\end{gathered}
$$

Kemudian data-data hasil penelitian dianalisis secara statistik menggunakan metode ANOVA (Analisis Of Variance) dengan tingkat kepercayaan 95\%. Dilanjutkan dengan uji LSD ( Least
Significant Difference) untuk mengetahui kelompok perlakuan yang berbeda signifikan dibandingkan dengan yang lainnya.

\section{HASIL DAN PEMBAHASAN}

\section{Hasil Penapisan Fitokimia}

Ekstrak etanol daun gedi merah positif mengandung senyawa bioaktif yang berperan dalam memberikan khasiat atau efek biologi, antara lain flavonoid, tanin, saponin, steroid.

Tabel 1. Hasil penapisan fitokimia ekstrak daun gedi merah

\begin{tabular}{ccc}
\hline NO & Metabolit & Hasil \\
& Sekunder & \\
\hline 1. & Flavanoid & + \\
2. & Alkaloid & - \\
3. & Steroid & + \\
4. & Saponin & + \\
5. & Tanin & + \\
\hline
\end{tabular}

\section{Hasil Perhitungan Rasio Bobot Ginjal}

Setelah perlakuan selama 10 hari, tikus dikorbankan dengan eter setelah itu dibedah dan difiksasi kedua ginjalnya secara hati-hati, selanjutnya dilakukan dengan cara menimbang bobot ginjal semua kelompok hewan uji serta perhitungan rasio bobot ginjal.

\begin{tabular}{|c|c|c|c|}
\hline Kelompoik & $\begin{array}{l}\text { Bobot ginat } \\
\text { (g) }\end{array}$ & $\begin{array}{c}\text { Bobot badas } \\
100 \mathrm{~g}\end{array}$ & $\begin{array}{l}\text { Rerata }=\mathrm{SD} \\
\text { Rasio Ginjal }\end{array}$ \\
\hline Keetrol Normal & $0.88=0.09$ & $2.41=0.63$ & $0.38=0.17$ \\
\hline $\begin{array}{l}\text { Keatrol Negatif }\left(\mathrm{N}_{1}\right. \\
\mathrm{CMC})\end{array}$ & $1,28 \pm 0,11$ & $2,39 \pm 0,59$ & $0,59=0,10$ \\
\hline $\begin{array}{l}\text { Koatrol Positif } \\
\text { (butugin eliksir) }\end{array}$ & $1,18 \pm 0,05$ & $2,44 \pm 0,08$ & $0,47 \times=0,02$ \\
\hline EDGM $50 \mathrm{mg} \mathrm{kg}$ BB & $0,99 \pm 0,01$ & $2,05 \pm 0,58$ & $0,50^{\circ}=0,12$ \\
\hline EDGM $100 \mathrm{mg} \mathrm{kg} B B$ & $1,12=0,02$ & $2,45=0,64$ & $0,45^{\circ}=0.14$ \\
\hline EDGM $150 \mathrm{mg} / \mathrm{g} \mathrm{BB}$ & $1,10 \pm 0,05$ & $2,72 \pm 0.63$ & $0,42^{\circ}=0,12$ \\
\hline
\end{tabular}

Tabel 2. Rataan Bobot Badan, Bobot Ginjal dan Rasio Bobot Ginjal

\begin{tabular}{|c|c|}
\hline Kelempok & $\begin{array}{l}\text { Pemuman Raio Bebot Giajal } \\
\qquad\left(\omega_{*}\right)\end{array}$ \\
\hline Rontrol pouitif (butupin alikeir) & 14,34 \\
\hline EDGM 50 mg kg an & 9,09 \\
\hline EDCM $100 \mathrm{mg} k g$ BB & 12,72 \\
\hline EDOM $150 \mathrm{mz} \mathrm{kz} B \mathrm{BB}$ & 25,63 \\
\hline
\end{tabular}

Tabel 3. Persentase Penurunan Rasio Bobot ginjal $\mathrm{g} / 100 \mathrm{~g} \mathrm{BB}$. 


\section{Hasil pengukuran Kadar Kalsium}

Rata-rata pengukuran kadar kalsium pada hewan uji dapat dilihat pada Tabel 4

Tabel 4. Hasil rata- rata kadar kalsium pada ginjal.

\begin{tabular}{|c|c|}
\hline Keiompok & $\begin{array}{c}\text { Rerata }=\text { SD kadar } \\
\text { kalsium (e) }\end{array}$ \\
\hline Nomul & $0,132^{5}=0,016$ \\
\hline Kontrolnegatif & $0,188=0,046$ \\
\hline Kontrol positif & $0,122^{\circ} \pm 0,008$ \\
\hline EDGM $50 \mathrm{mg} \mathrm{kg}$ BB & $0,071^{\circ}=0,022$ \\
\hline EDQM $100 \mathrm{mg} / \mathrm{kg}$ BB & $0,096^{\circ} \pm 0,008$ \\
\hline EDGM 150 as ks BB & $0,046^{*}=0,003$ \\
\hline
\end{tabular}

Ket: 1)Abjad yang sama menunjukkan adanya perbedaan yang tidak signifikan

2) Abjad yang berbeda menunjukkan tidak adanya perbedaan yang signifikan

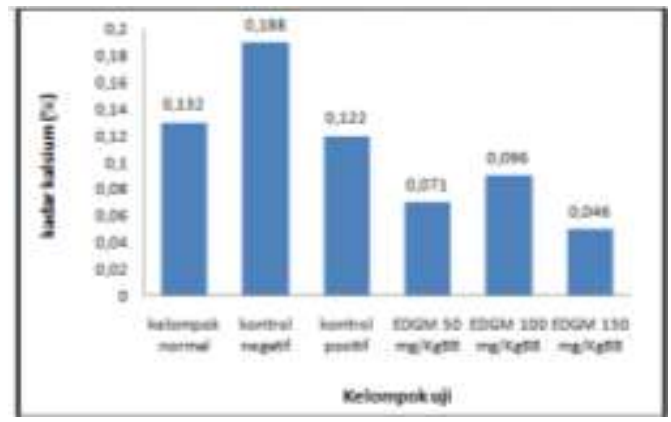

Gambar 1. Diagram rata-rata kadar kalsium ginjal

Adanya aktivitas penghambatan pembentukan batu ginjal diduga karena adanya aktivitas metabolit sekunder yang terdapat dalam ekstrak daun gedi merah yaitu flavonoid, tanin, steroid dan saponin. Hal ini didukung dengan hasil uji penapisan fitokimia pada Tabel 1 yang menunjukkan adanya golongan senyawa tersebut. Kemampuan daun gedi merah dalam melarutkan kalsium batu ginjal diduga karena adanya kandungan flavonoid yang terdapat di dalamnya. Kalsium pada batu ginjal dapat membentuk senyawa kompleks dengan gugus $-\mathrm{OH}$ dari flavonoid sehingga membentuk Ca-flavonoid. Senyawa kompleks ini diduga lebih mudah larut dalam air, sehingga air yang ada dalam urin akan membantu kelarutan batu tersebut (Suharjo dan Cahyono, 2009).

Pada penelitian ini hewan uji dibagi menjadi 6 kelompok, yang terdiri dari3 ekor tikus yang dibagi secara acak.
Kelompok I adalah kelompok normal yang diberikan NaCMC. Kelompok II adalah kontrol negatif yang diberi $\mathrm{Na} \mathrm{CMC}$. Kelompok III adalah kontrol positif yang diberikan batugin eliksir. Kelompok IV,V dan VI sebagai kelompok uji diberi ekstrak etanol daun gedi merah dengan konsentrasi masing-masing $50 \mathrm{mg} / \mathrm{kg} \mathrm{BB} ; 100 \mathrm{mg} / \mathrm{kg}$ $\mathrm{BB}$; dan $150 \mathrm{mg} / \mathrm{kg} \mathrm{BB}$ secara peroral. Setelah 2 jam kelompok 2-6 diberikan induksi batu ginjal.Semua perlakuan tersebut dilakukan selama 10 hari. Pada hari ke 10 setelah perlakuan tikus dipuasakan selama 16 jam, hanya diberikan air minum secukupnya saja. Pada hari ke 11 dilakukan pembedahan pada tikus. Terlebih dahulu tikus dikorbankan dengan menggunakan eter, selanjutnya abdomen dibuka kemudian diambil ginjalnya dan dilakukan penimbangan bobot ginjal. Menghitung rasio bobot ginjal/100g BB dengan cara menimbang ginjal tikus semua kelompok dan menghitung rasio bobot ginjal terhadap berat badan, rasio digunakan untuk menyetarakan atau mengoreksi faktor bobot badan yang lebih besar akan memiliki bobot ginjal yang besar pula, begitupun sebaliknya. Hasil perhitungannya dapat dilihat pada Tabel 2 .

Hasil uji statistik dengan metode ANOVA terhadap rasio bobot ginjal, dapat dilihat bahwa rasio bobot ginjal semua kelompok tidak berbeda signifikan ( $>0,05)$ kemudian dilanjutkan dengan uji LSD (Least Significantly Difference) menghasilkan data bahwa rasio bobot ginjal kelompok normal, kontrol negatif, kontrol positif, EDGM $50 \mathrm{mg} / \mathrm{KgBB}$, EDGM $100 \mathrm{mg} / \mathrm{KgBB}$ dan EDGM 150 $\mathrm{mg} / \mathrm{KgBB}$ tidak berbeda signifikan. Namun bila dilihat rata-rata rasio bobot ginjal kontrol negatif lebih tinggi dari semua kelompok baik kelompok normal, kontrol positif dan kelompok perlakuan. Rata-rata rasio bobot ginjal kontrol negatif yaitu sebesar 0,55. Hal ini disebabkan karena terjadinya peradangan dan mengandung banyak deposit kalsium. Berdasarkan hasil perhitungan penurunan rasio bobot ginjal pada Tabel 3 dapat dilihat bahwa kelompok kontrol positif mampu menurunkan rasio bobot ginjal mencapai $14,54 \%$ dari rasio kontrol 
negatif, ekstrak etanol daun gedi merah dosis $50 \mathrm{mg} / \mathrm{Kg}$ BB mampu menurunkan rasio bobot ginjal mencapai $9,09 \%$, ekstrak etanol daun gedi merah dosis $100 \mathrm{mg} / \mathrm{Kg}$ BB mampu menurunkan rasio bobot ginjal mencapai $12,72 \%$, dan pada dosis 150 $\mathrm{mg} / \mathrm{Kg}$ BB mampu menurunkan rasio mencapai $23,63 \%$. Adanya aktivitas anti radang dari ekstrak etanol daun gedi merah mampu menurunkan rasio bobot ginjal. Data rasio bobot ginjal tersebut menggambarkan bahwa nefrotoksik dapat menaikkan bobot ginjal akibat reaksi radang karena kadar kalsium yang tinggi dalam ginjal.

Selanjutnya dilakukan parameter pengukuran kandungan kalsium ginjal tikus menggunakan alat flame fotometer. Metode ini merupakan salah satu metode yang sering digunakan dalam pengujian kadar natrium, kalsium dan kalium, relatif sederhana, alat instrumen yang baik dan aman. Berdasarkan hasil pengukuran ratarata kadar kalsium pada Tabel 4 menunjukan bahwa bahwa kontrol negatif $(\mathrm{Na} \mathrm{CMC}+$ induksi etilen glikol $0,75 \%+$ amonium klorida $2 \%$ ) tidak memiliki efek terhadap penghambatan pembentukan batu ginjal karena tidak terjadi pengeluaran kalsium batu ginjal yang signifikan, dengan nilai persen kadar kalsium sebesar $(0,188 \pm 0,046) \%$. Untuk EDGM 50 $\mathrm{mg} / \mathrm{Kg}$ BB, EDGM $100 \mathrm{mg} / \mathrm{Kg}$ BB dan EDGM $150 \mathrm{mg} / \mathrm{kg}$ BB memiliki aktivitas dalam menghambat pembentukan batu ginjal dengan nilai persen kadar kalsium berturut-turut sebesar $(0,071 \pm 0,022) \%$, $(0,096 \pm 0,008) \%$ dan $(0,046 \pm 0,003) \%$.

Berdasarkan hasil analisis one way ANOVA terhadap kadar kalsium diperoleh nilai signifikansi $0,000(\mathrm{p}<0,05)$. Artinya masing - masing perlakuan memberikan perbedaan yang bermakna, untuk hal ini maka perlu dilanjutkan dengan uji LSD (Least Significantly difference). Uji LSDmenunjukkan bahwa kelompok normal tidak berbeda signifikan dengan kelompok kontrol positif tetapi berbeda signifikan dengan kelompok kontrol negatif, dengan kelompok EDGM pada ketiga varian dosis. Ketiga variasi dosis EDGM dapat menghambat pembentukan batu ginjal dengan kandungan kalsium yang tidak berbeda signifikan namun pada dosis EDGM $150 \mathrm{mg} / \mathrm{Kg}$ BB terlihat memiliki nilai kadar kalsium ginjal yang lebih rendah.Dapat disimpulkan bahwa, ekstrak etanol daun gedi merah memiliki aktivitas penghambatan pembentukan batu ginjal pada ketiga variasi dosis dan yang paling efektif adalah pada dosis 150 mgkgBB.

\section{DAFTAR PUSTAKA}

Anggreani, Sekar. (2013). Uji Aktivitas Pembenukan Batu Ginjal (Anti Nefrolithiasis) ekstrak Etanol dari Herba Pegagan (Centella asiatica (L.) Urban) Pada Tikus Putih Jantan, Fakultas Kedokteran dan Ilmu Kesehatan Program Studi Farmasi, Jakarta.

Anggara, A. (2009). Uji Aktivitas Anti Lithiasis Ekstrak Etanol Daun Alpukat (Persea americana Mill) Pada Tikus Putih Jantan, Fakultas Kedokteran Hewan, IPB, Bogor

Anonim, (2013). Riset Kesehatan Dasar, Jakarta

Ari, W.S., Bambang, S. (2006). Buku Ajar Penyakit Dalam Edisi IV, PP Departemen Ilmu Penyakit Dalam, Jakarta, 563

Arnida, \& Sutomo. (2008). Pengaruh Fraksi Bulbus Bawang Dayak (Eleutherine Palmifolia (L) Merr) terhadap Aktivitas Diuretika dan Peluruhan Batu Ginjal Tikus Putih Jantan, Farmasi FMIPA Universitas Lambung Mangkurat

Boesro, S., Warya, S., Rosdiana, T., \& Ade., Z. (2010). Development of Phytopharmaca Product Content of Combination of Extract Celery (Apium graveolens L) And Sambiloto, International Seminar Dan Expo On Jam, Faculity Of Pharmachy, Universitas Padjajaran Indonesia, Bandung 
Corwin, Elizabeth. (2009). Buku Saku Patofisiologi Corwin Edisi III, alih bahasa Nike Budhi, Penerbit Buku Kedokteran EGC, Jakarta.

Dama, E. (2014). Uji aktivitas daun gedi merah (Abelmoschus moschatus Medik) terhadap kelarutan kalsium batu ginjal secara In vitro, Universitas Tadulako, Palu.

Fadhila, (2013). Uji Toksisitas Akut (Lethal Dose ${ }_{50}$ ) Ekstrak Etanol Daun Gedi Merah (Abelmoschus manihot L.) Terhadap Tikus Putih Jantan Galur Wistar (Rattus norvegicus L.), Jurnal PHARMACON Ilmiah Farmasi-UNSRAT, 2(01),23-27.

Ganong, W.F. (1995). Buku Ajar Fisiologi Kedokteran, Edisi 14, Jakarta : Penerbit Buku Kedokteran ECG.

Ma'sum, Selvia. (2013). Uji Aktivitas Penghambat Batu Ginjal dari Ekstrak Etanol 70\% Daun Kapuk Randu (Ceiba Pentandra (L.) Gaertn) pada Tikus Jantan Putih, Fakultas Kedokteran dan Ilmu Kesehatan Program Studi Farmasi, Jakarta.

Nisma, F. (2011). Pengaruh penambahan ekstrak etanol $70 \%$ buah anggur biru (Vitis vinifera L) terhadap kelarutan kalsium batu ginjal, Farmasi FMIPA Uhamka

Shao-Yu, Z., Nai-Ning, S., Wen-Yuan, G., Wei, J., Hong-Quan, D., Pei-Gen, X., 2006, Progress in the treatment of chronic glomerulonephritis with traditional Chinese medicine, Asian Journal of Pharmacodynamic and Pharmacokinetics, 6 (4), 317 - 325.

Soeryoko, Hery. (2011), Tanaman Obat Paling Favorit Penghancur Batu Ginjal, Penerbit Andi, Yogyakarta.
Suharjo, B., \& Cahyono. (2009). Batu Ginjal, Kanisius, Yogyakarta. 